\title{
Krankenversicherung mit der Helsana-Gruppe
}

\author{
Profitieren Sie vom FMH Insurance Services Kollektivvertrag
}

\section{FMH Insurance Services Kollektivvertrag}

Treten Sie dem FMH Insurance Services Kollektivvertrag bei, welcher mit der Helsana-Gruppe abgeschlossen wurde. Die Helsana-Gruppe besteht aus folgenden Versicherungsgesellschaften: Helsana, Progrès, sansan, avanex und aerosana. Profitieren Sie und Ihre Familienmitglieder von den Topleistungen und den attraktiven Prämienrabatten.

\section{Ihre Vorteile auf einen Blick}

\section{Kollektivrabatte bei Helsana $20 \%$}

Helsana gewährt FMH-Mitgliedern auf den meisten Zusatzversicherungen einen Kollektivrabatt von 20\% gegenüber der Normalprämie.

Kollektivrabatte bei Progrès, sansan, avanex und aerosana $15 \%$

Die obengenannten Gesellschaften gewähren FMH-Mitgliedern auf den meisten Zusatzversicherungen einen Kollektivrabatt von $15 \%$ gegenüber der Normalprämie.

Sind Sie bereits bei einer Krankenversicherung der Helsana-Gruppe versichert? Wechseln Sie ganz einfach und ohne grossen Aufwand in den FMH Insurance Services Kollektivvertrag. Rufen Sie uns an, damit auch Sie in Zukunft von günstigeren Konditionen profitieren können.

\section{Profitieren Sie von unserem Angebot}

Nutzen Sie die Vorteile des FMH Insurance Services Kollektivvertrags und bestellen Sie noch heute Ihre persönliche Offerte mit dem untenstehenden Antworttalon (bitte eine aktuelle Policenkopie beilegen).

\section{Antworttalon}

Vorname/Name

Adresse

PLZ/Ort

Geburtsdatum

Telefon Privat/Geschäft

Beste Zeit für einen Anruf

E-Mail-Adresse

O Bitte senden Sie mir eine Offerte. (Bitte eine aktuelle Policenkopie beilegen!)

Ich wünsche eine persönliche Beratung. Bitte rufen Sie mich an.

Ich interessiere mich für folgende Produkte:

O Todesfallversicherung $\bigcirc$ Pensionskasse BVG

O Säule $3 a \quad O$ Rechtsschutzversicherung

O Finanz-/Steuerplanung $\bigcirc$ Berufshaftpflichtversicherung

○

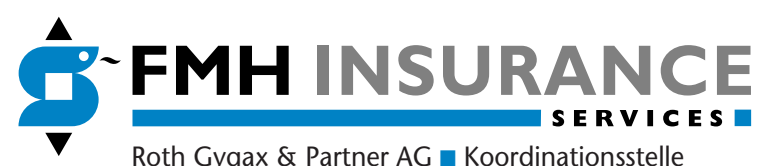

Roth Gygax \& Partner AG \& Koordinationsstelle Moosstrasse 2 - 3073 Gümligen 